\title{
Frequency System of Phonemes: Contrastive Analysis of Common Standard Persian and English Consonants in Context-Based Corpora
}

\author{
Ali Mansouri Nejad ${ }^{1} \&$ Mahmoud Qaracholloo ${ }^{1}$ \\ ${ }^{1}$ Ilam University, Iran \\ Correspondence: Ali Mansouri Nejad, Ilam University, Iran. E-mail: ali_mn1986@yahoo.com
}

Received: December 17, 2012

Accepted: January 17, 2013 Online Published: February 28, 2013

doi:10.5539/ass.v9n3p76

URL: http://dx.doi.org/10.5539/ass.v9n3p76

\begin{abstract}
This paper is concerned with the contrastive analysis of the frequency system of common standard Persian and English consonants. Two corpora were selected from Iranian newspapers. One of them is Keyhan newspaper that is published in Persian and the other one is Tehran Times newspaper that goes under press in English in Iran. Common standard Persian and English consonants were enumerated and analyzed by themselves and with respect to parts of speech, manner of articulation and place of articulation. Results indicated a significant difference between the frequency of eleven Persian consonants and their English counterparts. Nouns comprised the highest frequency of consonants and while prepositions, determiners and conjunctions had the lowest. With respect to manner of articulation, there was a significant difference between both languages in all manners with stops as the most frequent in both. As for the place of articulation, there was a significant difference between both languages and alveolars were the most frequent in both. Regarding manner of articulation, English stops and liquids were more frequent than those of Persian. With respect to place of articulation, just English alveolars were more frequent than the Persian ones. The frequency of all other places was higher in Persian. In spite of frequent differences between both languages, many similarities were also identified in terms of their frequency systems, and the frequency of consonants with respect to parts of speech, manner of articulation and place of articulation.
\end{abstract}

Keywords: phoneme, frequency system, consonants, place of articulation, manner of articulation, parts of speech

\section{Introduction}

The very initial notion of phonemes frequency came to notice in the early $20^{\text {th }}$ century when it was precisely elaborated on in an equation by Yule (1920, cited in Tambovtsev \& Martindale, 2007). Since then, the tendency to analyze phonemes of languages in terms of frequency has attracted so many researchers like Tambovtsev and Martindale (2007).

That is, based on a contrastive analysis hypothesis and in line with the principles of the structuralist view of language which stand for the various surface structure differences between languages, two or more languages would undergo contrastive analysis to formulate a framework whereby the difficulty level of target language learning would be recognized (Salehuddin, Kim Hua \& Maro, 2006; Ling \& Grabe, 1999; Giannoni, 2002; Yeh, 2004; Sajavaara \& Dufva, 2001; MacKay, Meador, \& Flege, 2001; Demirezen, 2010; Koo, 2011).

Different language levels, have been subject to such studies. Kuperman, Ernestus and Baayen (2008) explored how the acoustic duration of phonemic sequences and their frequency of occurrence are correlated. In a more recent study, Weinberger and Kunath (2009) studied the frequency of phonemes for a typology of English accents. A number of other researchers have studied the frequency of syllables and words (Ota, 2006; Macizo \& Van Petten, 2007; Santiago, Pérez, Palma, \& Stumberger, 2007). Davidson (2006) examined the influence of lexical frequency on accuracy and error types in the production of non-native phonotactics.

What should be added to the discussion of phonemes frequency system (FS) is that the notion of phonemes frequency ceases to take into account its relationship with other notions such as language learning and cognition. In fact, recently several studies have focused on the role played by phonemes frequency in second language acquisition. For example, Tsoi Wai Chuen (2005) carried out a study to investigate the influence of frequency of phonemes in the first language (L1) on target language acquisition (L2), particularly in terms of error analysis. 
Second language acquisition (SLA) is one of those applied linguistic domains affected by FS of phonemes. In other words, frequency of phonemes can highly contribute to error analysis in this way that low-frequent or high-frequent phonemes might differently influence learning a second or third language. According to Moates, Stockmal, and Bond (2004), phonemes frequency can have effect on the recognition of whole words, which is crucial in learning the target language. Some specialists have even transcended this fashionable way of analyzing phonemes. They have gone a long way to develop phonemic and syllabic frequency inventories (Sandoval, Toledano, Torre, Garrote, \& Guirao, 2007).

This study aims at investigating the FS of Persian and English. In so doing, the consonants of each language are analyzed in terms of parts of speech (PS), manner of articulation (MA), and place of articulation (PA). Moreover, the data extracted from the corpus of both languages will be compared in terms of PS, MA, and PA. (Note 1)

\subsection{Previous Studies on Phonemes}

The concepts of phonology and phonemes have been investigated in relation to different aspects of language learning (Timmer \& Schiller, in press; Jefferies, 2012) and phoneme awareness (Hogan, Bowles, Catts, \& Storkel, 2011; Newman, Tardif, Huang, \& Shu, 2011). One of the studies with the purpose of investigating the phoneme frequency of written Persian was carried out by Mousavi Torbati (1968). He investigated the frequency and the proportion of each Persian consonant and vowel among a whole of 45947 phonemes. His findings revealed that among consonants, $/ \mathrm{n} /$ with the frequency of 2893 (5.82) and among vowels, /a/ with the frequency of $5774(12.57)$ had the highest frequencies. $/ \check{z} /$ with a frequency of $40(0.08)$ and /u/ with a frequency of 671 (1.38) had the lowest frequencies among consonants and vowels respectively. In this study, consonants comprised 57 percent and vowels embodied 43 percent of the whole phonemes which is not an indication of a significant difference between the frequency of consonants and vowels.

In another research, Mohammadifar (1990) investigated the percentage of probability of consonants and vowels in written Persian. In his study, $/ \mathrm{r} /$ with the percentage of $5.63 \mathrm{and} / \mathrm{n} /$ and $/ \mathrm{d} /$ with the percentages 5.31 and 5.27 respectively had the highest and lowest frequencies among consonants. As for the vowels, /a/ with a percentage of 11.98 and $/ \mathrm{u} /$ with the percentage of 1.30 had the highest and lowest frequencies respectively. The findings of this study are in harmony with the results of Mousavi Torbati's (1968) study with respect to the frequency of vowels, but the results for the frequency of consonants are different and to some extent contradictory. In general, all phonemes in this study comprised 58.63 consonants, 40.90 vowels and 0.47 diphthongs.

Guirao and Jurado (1990) investigated the frequency of phonemes in American Spanish. Their study seemed to be a comprehensive and contributive one because it took a variety of phonemic features into account: 1) single phonemes, 2) distribution in the most frequent syllables, 3) syllables of initial and final positions, 4) distribution according to articulatory classes, 5) distribution according to MA as well as whether in initial or final word position. The corpus of the study was taken from five modern plays written by contemporary authors. The data collection procedure yielded a total of 163861 phonemes (Vowels: 79265 [48.4\%] and Consonants: 84576 [51.6\%]), 74460 syllables and 43306 words. In another fairly comprehensive study, Samareh (1993) investigated the frequency of consonants in CVCC consonant clusters at the beginning and end of syllables and beginning of consonant clusters. To do so, he divided consonants into fives groups: a) very active consonants including $/ \mathrm{r} /, / \mathrm{s} /$, /t/ with the minimum frequency of $160, \mathrm{~b}$ ) active consonants including $/ \mathrm{b} /, / \mathrm{f} /, / \mathrm{d} /, / \mathrm{m} /, / \mathrm{n} /$ and $/ ? /$ with the minimum frequency of 100, c) approximately active consonants $/ \mathrm{k} /, / \mathrm{l} /, / \mathrm{q} /, / \mathrm{v} /, / \mathrm{z} /, / \mathrm{x} /, / \mathrm{h} /, / \mathrm{j} /, / \mathrm{y} /$ and $/ \check{\mathrm{s}} /$ with the minimum and maximum frequencies of 50 and 97 respectively, d) less active consonants including /p/, /g/, /č/ with the minimum and maximum frequencies 20 and 44 respectively and finally e) the least active consonant $/ \check{z} /$ with the minimum frequency of 2 . In this study, /r/ with the frequency of 239 and $/ \check{z} /$ with the frequency of 2 had the highest and lowest frequencies respectively.

In an attempt to understand the way pair of names were ordered, Wright, Hay, and Bent (2003) analyzed a corpus of names such as Romeo and Juliet and experimental data. They figured out that gender bias, phonology, and frequency were contributing to the form of name ordering. Regarding the frequency, the more frequent names, male names, came first in a pair of names and the less frequent ones, female names came in the second position.

Tsoi Wai Chuen (2005), in a contributive and comprehensive study, attempted to determine the effect of occurrence frequency of phonemes on second language acquisition. More specifically, he believed that the replacement of the target language sounds with those of the native language by foreign language learners is not a haphazard phenomenon. He was avid to dig out the rules underlying the replacement by examining the frequent replacements in five target languages in terms of their articulatory features. In fact, the author was chasing the question whether the occurrence frequency of the phonemes in the native language affected these replacements in the target languages. It was found that, in terms of articulatory features, the most influential features in sound 
replacements were in this order: articulation $>$ voicing $>$ PA $>$ MA. As for the frequency of phonemes, it came out that the most frequent phonemes in the native language could lead to more sound replacements in the target language.

Monnin, lœvenbruck, and Beckman (2007) investigated the influence of frequency on word-initial obstruent acquisition in Hexagonal French. The study was carried out employing both written and oral frequency data of French, more clearly, a corpus of a written adult-directed speech, a corpus of oral adult-directed speech, and a corpus of oral child-directed speech. It was found that $/ \mathrm{s} /$ and $/ \mathrm{k} /$ were more frequent than $/ \mathrm{t} /$.

In a contrastive analysis, Assadi (2007) juxtaposed colloquial Persian with formal Persian so that the frequency of deletion and occurrence of sounds in colloquial Persian became transparent. The study was built on a corpus of 20-minitue conversations of native speakers from Tehran. In accord with the result of the study, it was revealed that colloquial Persian had 6 percent of sounds deleted. Among the deleted sounds consonants were more subject to be eliminated than vowels. Moreover, the dental sounds had the largest share among consonants.

Regarding the frequency of phonemes, Mansouri (2009) probed the FS of phonemes in oral and written Persian. $\mathrm{He}$ also examined the frequency of phonemes and syllables in 517 Iranian names (257 female names and 260 male names). Moreover, the frequency of phonemes in cities names was analyzed. A corpus of 236 names of cities was taken into account.

\subsection{Statement of the Problem}

Despite many attempts, there is no scholarly research available in the literature dealing with each language in terms of PS, MA and PA. Since phonemes of a language are produced in a unique way, there must be major differences between and among languages from a phonemic perspective. The phonemic differences are mainly derived from the way each organ of speech acts in the vocal tract to articulate each phoneme. Therefore, studying phonemes of a language in terms of PA an MA can lead to useful findings for linguists who are interested in some typological rules governing the systems of languages on the one hand and applied linguists and language teachers who aim to develop theories and apply those theories to language curricula on the other hand.

In addition, no study is found in the literature focusing on the role of PS. All PS are not in the same level of difficulty for students to cope with. In more clear terms, language learners learn some word types more easily and sooner. Studying phonemes of a language in terms of PS may result in some relationships between the phonemic and lexical features of a language. The present study intended to investigate the FS of consonants in Persian and English both intra-linguistically and inter-linguistically and with a focus on PS, MA, and PA.

\section{Method}

\subsection{The Corpora}

In order to carry out the study, two written discourse fragments were selected. These corpora were taken from two newspapers that have been published in Iran for long, one in Persian named Keyhan and the other one in English named Tehran Times. The rationales for the selection of these newspapers were their popularity among Iranians, error-free texts which undergo successive edition before publication, and their age-old circulation. The Persian discourse fragment taken from Keyhan had been printed on July 11, 2009, and the English one from Tehran Times on July 12, 2009.

\subsection{Procedure of Data Collection}

To pile up enough data for the study, some parts of the newspapers were read. These parts were equal to a total of 10280 PSs; 5140 Persian PSs and 5140 English PSs. Then, among these PSs, the number of common standard

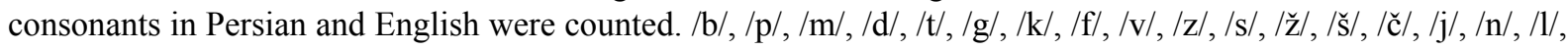
$/ \mathrm{r} /, / \mathrm{h} /$, and $/ \mathrm{y} /$ were common in the phonemic system of two languages. The total number of enumerated consonants in both Persian and English newspapers were 27751, 16142 Persian consonants and 11609 English consonants. Later on, all the extracted consonants were categorized according to the kind of PS (nouns, adjectives, adverbs, verbs, pronouns, prepositions, determiners, and conjunctions).

Due to many surface structure variations existing between Persian and English and an incomplete one-to-one harmony between Persian and English PSs, categorizing the consonants in terms of PSs was not too easy to perform and necessitated a more elaborate procedure. It was tried to develop a cross-linguistically consistent framework. For example, this in this book is regarded as adjective in Persian but English grammarians view that as determiner. More specifically, the attempt was to override such cross-linguistic differences to yield a unified procedure.

In case of Persian, many verbs, nouns, adjectives, pronouns, prepositions and determiners were classified in such 
a way to cooperate in the procedural purpose of this study. To say, verbs receive prefixes and suffixes, in different tenses and have different functions, such as mi-xor-im (we eat) or be-xor-im (we should eat). $m i$ and $b i$ are prefixes and $i m$ is suffix. Verbs also appear in compound and group forms like, dar-raft (he escaped), sogand mixoram (I swear) and az dastam raft (I lost it). Verbs in each variation were regarded as a single PS. As for nouns, indefinite nouns, such as ketãb-i (a book), plural nouns with suffixes like ketãb-hã (books) and compound nouns like dãneš ãmuz (student) were considered as one class. For adjectives, simple adjectives like sefid (white), adjectives with prefixes such as bi-xerad (stupid), comparative adjectives like sefid-tar (whiter), superlative adjectives such as sefid-tarin (the whitest) and compound adjectives like xoš barxord (good-tempered) were considered as one class as well. Compound adverbs like piš az ãnkeh (before), dar hãli keh (while) were also regarded as a single class. In Persian, adjectives and adverbs are sometimes used interchangeably depending on the semantic context; it was tried not to misclassify them due to their phonological similarities. Like English, in Persian pronouns are personal or impersonal and personal nouns themselves are of two kinds, unbound like man (I) and bound like am in ketãb-am (my book). Of course, in English the bound pronoun is regarded as possessive adjective. In this study, since the bound pronoun of Persian is not an independent part, the bound pronoun with the word that it sticks to was regarded as one class. Group prepositions like be xãtereh (for), bar tebqeh (according to) were classified as one class. Connectives, conjunctions, and interjections were classified under one class as conjunction. Finally words like in in in ketãa (this book), ãn in ãn ketãb (that book) were regarded as determiner (Khanlari, 2007; Khanlari, 2000; Arzhang, 2000).

As for English, a similar trend was followed. Auxiliaries (might, could, can), verbs with particles (stand up, sit down, gerunds (going), infinitives (to go), and third-person singulars (takes) were considered as a single class. Plural nouns (books), compound nouns (dining room, mother-in-law), and genitive cases (George's) were regarded as a single class named noun. Personal pronouns, reflective and emphatic pronouns (myself, yourself), possessive pronouns (mine, yours), demonstrative pronouns (those, these), relative pronouns (which, that), and interrogative pronouns (who, which) came under the category of pronouns. Numeral adjectives (twelfth), interrogative adjectives (what in what film), and distributive adjectives (each in each man) were classified as adjectives. Adverbs of time (tomorrow), adverbs of place (inside), adverbs of manner (hard), adverbs of quantity (many), adverbs of reason (therefore), adverbs of number (twice), adverbs of affirmation and negation (yes and not respectively), intensive adverbs (just), interrogative adverbs (how long), and relative adverbs (where, when) went under the category of adverbs. Prepositions were of different kinds: simple prepositions (to and for), compound prepositions (because of), participle prepositions (notwithstanding and concerning), prepositions for manner, place and time (about, up and during). The conjunction class included commutative conjunctions (and, and then), adversative conjunctions (but), illative conjunctions (hence), alternative conjunctions (otherwise), explanatory conjunctions (such as), and subordinate conjunctions (as if). Finally, lexical units like that in that book, this in this book and two in two books were counted as determiners.

\subsection{The Procedure of Data Analysis}

The collected data underwent some descriptive and inferential procedures utilizing SPSS (statistical package for social sciences) software. First of all, a descriptive analysis of the total number of consonants in each language was yielded. Later on, the frequency of each consonant in each language was analyzed in comparison to the total number of consonants in the same language. Then, an $\mathrm{x}^{2}$ was run to indicate the probable difference between the frequency of each consonant in Persian and English. Next to that consonants were analyzed in terms of PSs. This was a three-dimensional process. In so doing, the percentage of each consonant in different PSs, the percentage of different consonants in each PS, and the percentage of each consonant in each PS to all consonants in all PSs were calculated separately. After that, the percentage of each consonant in each language with respect to MA was calculated. Next, $\mathrm{x}^{2}$ was run to look for the probable differences in the frequencies of English and Persian consonants regarding their MAs. Finally, the percentage of consonants in each language with respect to their PSs was calculated and $\mathrm{x}^{2}$ was run to look for the probable frequency differences between Persian and English.

\section{Results}

\subsection{The FS of Persian and English Consonants}

The total number of consonants in the Persian corpus was 16142 . The highest frequency belonged to /r/ (2041, 12.64 percent $)$ and $/ \mathrm{n} /(1652,10.23$ percent). $/ \check{z} /(14,0.08$ percent $)$ and $/ \check{c} /(74,0.45$ percent $)$ had the lowest frequencies. Other consonants were normally distributed along the continuum (Table 1).

The total number of consonants in English newspaper was 11609. $/ \mathrm{r} /(1618,13.93$ percent $)$ and $/ \mathrm{n} /(1574,13.55$ percent) had the highest frequencies. $/ \check{z} /(15,0.12$ percent $)$ and $/ \check{c} /(57,0.49$ percent $)$ had the lowest frequency. Other consonants were normally distributed along the continuum (Table 1). 
Table 1. The frequency of consonants across English and Persian PSs and in general

\begin{tabular}{|c|c|c|c|c|c|c|c|c|c|c|c|c|c|c|c|c|c|c|}
\hline & \multicolumn{2}{|c|}{ NOUN } & \multicolumn{2}{|c|}{ ADJ } & \multicolumn{2}{|c|}{ PREP } & \multicolumn{2}{|c|}{$\mathrm{ADV}$} & \multicolumn{2}{|c|}{ PRON } & \multicolumn{2}{|c|}{ VERB } & \multicolumn{2}{|c|}{ DET } & \multicolumn{2}{|c|}{ CONJ } & \multicolumn{2}{|c|}{ Total } \\
\hline & $\mathrm{E}$ & $\mathrm{P}$ & $\mathrm{E}$ & $\mathrm{P}$ & $\mathrm{E}$ & $\mathrm{P}$ & $\mathrm{E}$ & $\mathrm{P}$ & $\mathrm{E}$ & $\mathrm{P}$ & $\mathrm{E}$ & $\mathrm{P}$ & $\mathrm{E}$ & $\mathrm{P}$ & $\mathrm{E}$ & $\mathrm{P}$ & $\mathrm{E}$ & $\mathrm{P}$ \\
\hline$/ \mathrm{p} /$ & 306 & 111 & 66 & 21 & 16 & 2 & 17 & 15 & 0 & 0 & 81 & 19 & 0 & 0 & 0 & 0 & 486 & 168 \\
\hline$/ \mathrm{b} /$ & 145 & 226 & 37 & 89 & 20 & 271 & 8 & 33 & 0 & 0 & 79 & 95 & 1 & 17 & 13 & 9 & 303 & 740 \\
\hline$/ \mathrm{m} /$ & 270 & 841 & 46 & 255 & 41 & 8 & 11 & 43 & 9 & 19 & 58 & 175 & 30 & 29 & 0 & 11 & 465 & 1381 \\
\hline /f/ & 139 & 193 & 34 & 58 & 91 & 0 & 8 & 14 & 4 & 0 & 31 & 47 & 7 & 2 & 9 & 0 & 323 & 313 \\
\hline$/ \mathrm{v} /$ & 75 & 243 & 28 & 60 & 111 & 10 & 11 & 13 & 1 & 13 & 62 & 76 & 10 & 2 & 2 & 205 & 300 & 622 \\
\hline$/ \mathrm{t} /$ & 658 & 900 & 183 & 223 & 184 & 39 & 60 & 40 & 73 & 0 & 194 & 245 & 14 & 12 & 47 & 0 & 1413 & 1459 \\
\hline$/ \mathrm{d} /$ & 328 & 605 & 99 & 156 & 23 & 207 & 16 & 35 & 0 & 27 & 334 & 494 & 12 & 29 & 105 & 0 & 917 & 1553 \\
\hline$/ \mathrm{n} /$ & 734 & 961 & 243 & 207 & 203 & 26 & 52 & 62 & 5 & 62 & 165 & 244 & 61 & 90 & 111 & 0 & 1574 & 1652 \\
\hline$/ 1 /$ & 462 & 486 & 144 & 178 & 5 & 12 & 70 & 31 & 4 & 1 & 155 & 27 & 10 & 5 & 8 & 6 & 822 & 746 \\
\hline$/ \mathrm{r} /$ & 927 & 1139 & 209 & 255 & 141 & 316 & 75 & 49 & 12 & 7 & 213 & 239 & 29 & 36 & 12 & 0 & 1618 & 2041 \\
\hline$|z|$ & 351 & 294 & 14 & 81 & 14 & 144 & 10 & 44 & 19 & 4 & 162 & 49 & 9 & 0 & 7 & 1 & 586 & 616 \\
\hline$/ \mathrm{s} /$ & 666 & 570 & 126 & 132 & 11 & 19 & 62 & 36 & 33 & 0 & 200 & 164 & 47 & 2 & 0 & 0 & 1145 & 923 \\
\hline$/ \check{\mathbf{S}} /$ & 110 & 330 & 33 & 75 & 0 & 0 & 4 & 5 & 2 & 8 & 15 & 144 & 0 & 2 & 0 & 0 & 164 & 564 \\
\hline $\mid \check{\mathbf{z}} /$ & 9 & 10 & 6 & 3 & 0 & 0 & 0 & 1 & 0 & 0 & 0 & 0 & 0 & 0 & 0 & 0 & 15 & 14 \\
\hline$/ \check{c} /$ & 28 & 32 & 6 & 5 & 0 & 0 & 1 & 8 & 7 & 12 & 14 & 3 & 1 & 14 & 1 & 0 & 57 & 74 \\
\hline$/ \mathrm{j} /$ & 97 & 222 & 19 & 42 & 0 & 2 & 0 & 6 & 0 & 10 & 16 & 29 & 0 & 1 & 0 & 0 & 132 & 312 \\
\hline$/ g /$ & 148 & 155 & 41 & 27 & 7 & 2 & 8 & 12 & 0 & 1 & 27 & 53 & 0 & 11 & 0 & 0 & 231 & 261 \\
\hline$/ \mathrm{k} /$ & 441 & 315 & 109 & 91 & 11 & 3 & 10 & 15 & 0 & 104 & 129 & 87 & 9 & 31 & 3 & 2 & 712 & 648 \\
\hline$/ y /$ & 74 & 426 & 21 & 68 & 0 & 66 & 3 & 7 & 0 & 7 & 13 & 37 & 3 & 33 & 0 & 0 & 114 & 644 \\
\hline$/ \mathrm{h} /$ & 96 & 914 & 15 & 145 & 0 & 75 & 4 & 58 & 54 & 30 & 61 & 157 & 0 & 32 & 3 & 0 & 233 & 1411 \\
\hline Total & 6038 & 8973 & 1478 & 2171 & 878 & 1202 & 430 & 527 & 223 & 305 & 2007 & 2384 & 243 & 348 & 320 & 234 & 11609 & 16142 \\
\hline
\end{tabular}

Note: $\mathrm{E}=$ English, $\mathrm{P}=$ Persian, $\mathrm{ADJ}=$ adjective, $\mathrm{PREP}=$ preposition, $\mathrm{ADV}=$ adverb, $\mathrm{PRON}=$ pronoun, $\mathrm{DET}=$ determiner, $\mathrm{CONJ}=$ conjunction.

Results of the $\mathrm{x}^{2}$ indicated that there was a significant difference between the frequency of eleven Persian and English consonants. There was found a significant difference between the frequencies of the following consonants: /p/, /b/, /m/, /d/, /r/, /v/, /s/, /s/, /j/, /y/, and /h/. Persian consonants, /b/, /m/, /d/, /r/, /v/, /s/, /j/, /y/, and $/ \mathrm{h} /$ were more frequent than their English counterparts while in consonants $/ \mathrm{p} /$ and $/ \check{\mathrm{s}} /$ it was English that had the higher frequencies. The highest difference was found between Persian consonants $/ \mathrm{m} /(1381)$ and $/ \mathrm{h} /(1411)$ and their English counterparts $(/ \mathrm{m} / 465, / \mathrm{h} / 233)$. No significant difference was found between Persian and English consonants $/ \mathrm{f} /, / \mathrm{t} /, / \mathrm{m} /, / \mathrm{l} /, / \mathrm{z} /, / \mathrm{g} /, / \mathrm{k} /, / \check{\mathrm{z}} /$, and $/ \check{\mathrm{c}} /$. The least difference was obvious in $/ \mathrm{f} /, / \check{\mathrm{z}} /$, and $/ \check{\mathrm{c}} /$ (Tables 1,2 , 4) (See also Appendix, Figure 1).

Table 2. Results of $x^{2}$ for the distribution of consonants in English and Persian

\begin{tabular}{|c|c|c|c|c|c|c|c|c|c|c|c|c|c|c|c|c|c|c|c|c|}
\hline & $\mathrm{p}$ & $\mathrm{b}$ & $\mathrm{m}$ & $\mathrm{f}$ & $\mathrm{v}$ & $\mathrm{t}$ & $\mathrm{d}$ & $\mathrm{n}$ & 1 & $\mathrm{r}$ & $\mathrm{z}$ & $\mathrm{s}$ & $\check{s}$ & $\check{z}$ & $\check{\mathrm{c}}$ & $\mathrm{j}$ & $\mathrm{g}$ & $\mathrm{k}$ & $\mathrm{y}$ & $\mathrm{h}$ \\
\hline$\tilde{x}$ & $\begin{array}{l}0 \\
\stackrel{+}{2} \\
\text {. }\end{array}$ & $\begin{array}{l}\stackrel{\partial}{\dot{\infty}} \\
\stackrel{\infty}{\infty}\end{array}$ & \begin{tabular}{l}
$\tilde{~}$ \\
\multirow{+}{*}{} \\
$\dot{y}$
\end{tabular} & in & $\stackrel{\text { fo }}{\stackrel{I}{J}}$ & $\stackrel{\tilde{c}}{\imath}$ & $\begin{array}{l}a \\
\stackrel{0}{0} \\
\text { in }\end{array}$ & 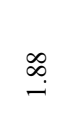 & $\begin{array}{l}+ \\
\text { \$ } \\
\text { d }\end{array}$ & $\begin{array}{l}\vec{a} \\
\dot{\alpha} \\
\dot{\alpha}\end{array}$ & 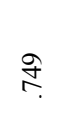 & $\begin{array}{l}\tilde{\infty} \\
\tilde{\infty} \\
\tilde{\tilde{C}}\end{array}$ & $\begin{array}{l}\stackrel{\otimes}{\infty} \\
\stackrel{0}{\sim} \\
0\end{array}$ & है. & $\begin{array}{l}\text { ते } \\
\text { ते }\end{array}$ & $\begin{array}{l}\text { s. } \\
\text { ì }\end{array}$ & $\stackrel{\text { ळे }}{\rightarrow}$ & $\stackrel{I}{a}$ & $\begin{array}{l}\mathscr{D} \\
\infty \\
n \\
o \\
\infty\end{array}$ & $\begin{array}{l}\stackrel{8}{ } \\
\stackrel{+}{+} \\
\dot{J}\end{array}$ \\
\hline $\begin{array}{l}\mathscr{O} \\
\text { ]్ }\end{array}$ & * & $*$ & $*$ & & $*$ & & $*$ & & & * & & $*$ & $*$ & & & $*$ & & & * & $*$ \\
\hline 茍 & 8 & 8 & 8 & ธี & 8 & $\overrightarrow{\mathrm{d}}$ & 8 & $?$ & $\tilde{b}$ & 8 & 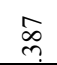 & 8 & 8 & $\tilde{\infty}$ & $\hat{m}$ & 8 & 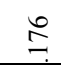 & 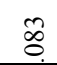 & 8 & 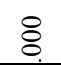 \\
\hline
\end{tabular}




\subsection{The FS of Persian and English Consonants with Respect to PSs}

As the analysis of data according to PSs was three-dimensional, first of all, the results of the frequency of each Persian and English consonant in different PSs are summarized. In case of Persian, in all consonants, nouns had the highest frequency with the average of 55.58 percent. Except $/ \mathrm{b} /, / \mathrm{m} /, / \mathrm{v} /, / 1 /$, and $/ \mathrm{z} /$, other consonants had the lowest frequency in conjunctions with the average of 1.44 percent. $/ \mathrm{b} /$ and $/ 1 /$ had the lowest frequencies in pronouns while $/ \mathrm{z} /$ and $/ \mathrm{v} /$ had the lowest frequencies in determiners. $/ \mathrm{m} /$ had the lowest frequency in prepositions. Among some consonants, the lowest frequency had been shared in several PSs. /p/ had the lowest frequency shared by pronouns, determiners and conjunctions. While $/ \mathrm{t} /$ and $/ \mathrm{s} /$ had equally the lowest frequencies in pronouns and conjunctions, $/ \check{\mathrm{s}} /$ and $/ \check{c} /$ equally had the lowest frequency in prepositions and conjunctions. In /ž/, except nouns, adjective, and adverbs, other PSs had no frequency (Table 3, see also Appendix, Figure 2).

As for the English consonants, in all consonants, nouns had the highest frequency with the average of 52.01 percent except $/ \mathrm{d} /$ which had the highest frequency in verbs (36.42). Except $/ \mathrm{t} /, / \mathrm{m} /, / \mathrm{s} /, / \breve{s} /, / \check{c} /, / \mathrm{h} /$ and $/ \mathrm{z} /$, other consonants had the lowest frequency in pronouns with the average of 1.92 percent. $/ \mathrm{m} /, / \mathrm{s} /, / \breve{s} /$, and $/ \mathrm{z} / \mathrm{had}$ the lowest frequencies in conjunctions. $/ \mathrm{t} /$ and $/ \mathrm{h} / \mathrm{had}$ the lowest frequencies in determiners. /č/ had the lowest frequency in prepositions. Among some consonants, the lowest frequency was apportioned among several PSs. To say more clearly, $/ \mathrm{p} /$ and $/ \mathrm{g} /$ had the lowest frequency shared by pronouns, determiners and conjunctions. While $/ \mathrm{r} /$ had equally the lowest frequencies in pronouns and conjunctions, / $/ \mathbf{s} /$ equally had the lowest frequency in prepositions, determiners, and conjunction. In /ž/, except nouns, adjectives, other PSs had no frequency. $/ \mathrm{j} / \mathrm{had}$ no frequency in prepositions, adverbs, pronouns, determiners, and conjunctions. In addition, $/ \mathrm{y} /$ included no frequency in prepositions, pronouns, and conjunctions. Finally /h/ did not own any frequency in prepositions and determiners (Table 3 ).

Table 3. The percentage of Persian and English consonants in different PSs

\begin{tabular}{|c|c|c|c|c|c|c|c|c|c|c|c|c|c|c|c|c|}
\hline & \multicolumn{2}{|c|}{ NOUN } & \multicolumn{2}{|c|}{ ADJ } & \multicolumn{2}{|c|}{ PREP } & \multicolumn{2}{|c|}{$\mathrm{ADV}$} & \multicolumn{2}{|c|}{ PRON } & \multicolumn{2}{|c|}{ VERB } & \multicolumn{2}{|c|}{ DET } & \multicolumn{2}{|c|}{$\mathrm{CONJ}$} \\
\hline & E & $\mathrm{P}$ & E & $\mathrm{P}$ & E & $\mathrm{P}$ & $\mathrm{E}$ & $\mathrm{P}$ & E & $\mathrm{P}$ & E & $\mathrm{P}$ & $\mathrm{E}$ & $\mathrm{P}$ & $\mathrm{E}$ & $\mathrm{P}$ \\
\hline$/ \mathrm{p} /$ & 62.96 & 66.07 & 13.58 & 12.50 & 3.29 & 1.19 & 3.49 & 8.92 & 0 & 0 & 16.66 & 11.30 & 0 & 0 & 0 & 0 \\
\hline$/ \mathrm{b} /$ & 29.83 & 30.54 & 7.61 & 12.2 & 4.11 & 36.62 & 1.64 & 4.45 & 0 & 0 & 16.25 & 12.83 & 0.20 & 2.29 & 2.67 & 1.21 \\
\hline$/ \mathrm{m} /$ & 58.06 & 60.89 & 9.89 & 18.46 & 8.81 & 0.05 & 2.36 & 3.11 & 1.93 & 1.37 & 12.47 & 12.67 & 6.45 & 2.09 & 0 & 0.79 \\
\hline$/ \mathrm{f} /$ & 43.03 & 61.66 & 10.52 & 18.53 & 28.17 & 0 & 2.47 & 4.47 & 1.23 & 0 & 9.59 & 15.01 & 2.16 & 0.63 & 2.78 & 0 \\
\hline$/ \mathrm{v} /$ & 25 & 39.06 & 9.33 & 9.64 & 37 & 1.60 & 3.66 & 2.09 & 0.33 & 2.09 & 20.66 & 12.21 & 3.33 & 0.32 & 0.66 & 32.95 \\
\hline$/ \mathrm{t} /$ & 46.56 & 61.68 & 12.95 & 15.28 & 13.02 & 2.67 & 4.24 & 2.74 & 5.16 & 0 & 13.72 & 16.79 & 0.99 & 0.82 & 3.32 & 0 \\
\hline$/ \mathrm{d} /$ & 35.76 & 38.95 & 10.79 & 10.04 & 2.50 & 13.32 & 1.74 & 2.25 & 0 & 1.73 & 36.42 & 31.80 & 1.30 & 1.86 & 11.45 & 0 \\
\hline$/ \mathrm{n} /$ & 46.63 & 58.17 & 15.43 & 12.53 & 12.89 & 1.57 & 3.30 & 3.75 & 0.31 & 3.75 & 10.48 & 14.76 & 3.87 & 5.44 & 7.05 & 0 \\
\hline$/ 1 /$ & 56.20 & 65.14 & 17.51 & 23.86 & 0.60 & 1.60 & 8.51 & 4.15 & 0.48 & 0.13 & 18.85 & 3.61 & 1.21 & 0.67 & 0.97 & 0.80 \\
\hline$/ \mathrm{r} /$ & 57.29 & 55.80 & 12.91 & 12.49 & 8.71 & 15.48 & 4.63 & 2.40 & 0.74 & 0.34 & 13.16 & 11.70 & 1.79 & 1.76 & 0.74 & 0 \\
\hline$|z|$ & 59.89 & 47.72 & 2.38 & 13.14 & 2.38 & 23.37 & 17.06 & 7.14 & 3.24 & 0.64 & 27.64 & 7.95 & 1.53 & 0 & 1.19 & 0.16 \\
\hline$/ \mathrm{s} /$ & 58.16 & 61.75 & 11 & 14.30 & 0.96 & 2.05 & 5.41 & 3.90 & 2.88 & 0 & 17.46 & 17.76 & 4.10 & 0.21 & 0 & 0 \\
\hline$/ \check{\mathbf{s}} /$ & 67.07 & 58.51 & 20.12 & 13.29 & 0 & 0 & 2.43 & 0.88 & 1.21 & 1.41 & 9.14 & 25.53 & 0 & 0.35 & 0 & 0 \\
\hline $\mid \check{\mathbf{z}} /$ & 60 & 71.42 & 40 & 21.42 & 0 & 0 & 0 & 7.14 & 0 & 0 & 0 & 0 & 0 & 0 & 0 & 0 \\
\hline$/ \check{c} /$ & 49.12 & 43.24 & 10.52 & 6.75 & 0 & 0 & 1.75 & 10.81 & 12.28 & 16.21 & 24.56 & 4.05 & 1.75 & 18.91 & 1.75 & 0 \\
\hline$/ \mathrm{j} /$ & 73.48 & 71.15 & 14.39 & 13.46 & 0 & 0.64 & 0 & 1.92 & 0 & 3.20 & 12.12 & 9.29 & 0 & 0.32 & 0 & 0 \\
\hline$/ \mathrm{g} /$ & 64.06 & 59.38 & 17.74 & 10.34 & 3.03 & 0.76 & 3.46 & 4.59 & 0 & 0.38 & 11.68 & 20.30 & 0 & 4.21 & 0 & 0 \\
\hline$/ \mathrm{k} /$ & 61.93 & 48.61 & 15.30 & 14.04 & 1.54 & 0.46 & 1.40 & 2.31 & 0 & 16.04 & 18.11 & 13.42 & 1.26 & 4.78 & 0 & 0.30 \\
\hline$/ \mathrm{y} /$ & 64.91 & 66.14 & 18.42 & 10.55 & 0 & 10.24 & 2.63 & 1.08 & 0 & 1.08 & 11.40 & 5.74 & 2.63 & 5.12 & 0 & 0 \\
\hline$/ \mathrm{h} /$ & 41.20 & 64.77 & 6.43 & 10.27 & 0 & 5.31 & 1.71 & 4.11 & 23.17 & 2.12 & 26.18 & 11.12 & 0 & 2.26 & 1.28 & 0 \\
\hline average & 52.01 & 55.58 & 12.73 & 13.44 & 7.56 & 7.44 & 3.70 & 3.26 & 1.92 & 1.88 & 17.28 & 14.76 & 2.09 & 2.15 & 2.75 & 1.44 \\
\hline
\end{tabular}


In the second dimension of data analysis according to PSs, more clearly, the frequency of different Persian and English consonants in the same PS, the following results came out. With respect to Persian consonants, among nouns, $/ \mathrm{r} /$ and $/ \check{z} /$ had the highest and the lowest frequencies respectively. $/ \mathrm{m} /$ and $/ \check{z} /$ had the highest and the lowest frequencies in adjectives. Regarding prepositions, $/ \mathrm{r} /$ had the highest frequency, but no frequency had been found in $/ \mathrm{v} /, / \breve{s} /, / \breve{z} /$, and $/ \check{c} /$. In the realm of adverbs, the highest and the lowest frequencies belonged to $/ \mathrm{n} /$ and $/ \check{z} /$. $/ \mathrm{k} /$ was outstanding in pronouns while $/ \mathrm{p} /, / \mathrm{b} /, / \mathrm{f} /, / \mathrm{t} /, / \mathrm{s} /$, and $/ \check{z} /$ had no frequency. The most frequently used consonant among verbs was /d/ while /ž/ again had no frequency. Like adverbs, among determiners $/ \mathrm{n} / \mathrm{was}$ frequent consonants, but $/ \mathrm{p} /, \mid \mathrm{z} /$, and $/ \check{\mathrm{z}} /$ were out of arena. Finally conjunctions indicated $/ \mathrm{v} /$ as the highly frequent consonant while except $/ \mathrm{k} /, / \mathrm{z} /, / 1 /, / \mathrm{v} /, / \mathrm{m} /$, and $/ \mathrm{b} /$ other consonants had no frequency (Table 4 ).

Concerning the frequency of different English consonants in the same PS, the following results came out. Among nouns, $/ \mathrm{r} /$ and $/ \check{z} /$ had the highest and the lowest frequencies respectively. $/ \mathrm{n} /, / \check{z} /$ and $/ \check{c} /$ had the highest and the lowest frequencies in adjectives. Regarding prepositions, $/ \mathrm{n} /$ had the highest frequency, but no frequency had been found in $/ \mathrm{y} /, / \mathrm{h} /, / \mathrm{j} /, / \breve{s} /, / \breve{z} /$, and $/ \check{c} /$. In the realm of adverbs, the highest and the lowest frequencies belonged to $/ \mathrm{r} /$ and $/ \check{z} /$ and $/ \mathrm{j} /$ with no frequency. $/ \mathrm{t} /$ was the highly frequent consonant in pronouns while $/ \mathrm{p} /, / \mathrm{b} /$, $/ \mathrm{d} /, / \mathrm{j} /, / \mathrm{g} /, / \mathrm{k} /, / \mathrm{y} /$, and $/ \check{z} /$ had no frequency. The most frequently used consonant among verbs was $/ \mathrm{d} /$ while $/ \check{z} /$ again had no frequency. Among determiners $/ \mathrm{n} /$ was the most frequent consonant, but $/ \mathrm{p} /, / \mathrm{h} /, / \mathrm{j} /, / \breve{s} /, / \mathrm{g} /$, and $/ \check{z} /$ were out of arena. Finally $/ \mathrm{n} /$ had been realized as the highly frequent consonant among consonants while $/ \mathrm{m} /$, /p/,/s/, /j/, /g/, /y/, /šs, and /ž/ had no frequency (Table 4).

Table 4. The percentage of different Persian and English consonants in the same PS

\begin{tabular}{|c|c|c|c|c|c|c|c|c|c|c|c|c|c|c|c|c|c|c|}
\hline & \multicolumn{2}{|c|}{ NOUN } & \multicolumn{2}{|c|}{ ADJ } & \multicolumn{2}{|c|}{ PREP } & \multicolumn{2}{|c|}{$\mathrm{ADV}$} & \multicolumn{2}{|c|}{ PRON } & \multicolumn{2}{|c|}{ VERB } & \multicolumn{2}{|c|}{ DETER } & \multicolumn{2}{|c|}{$\mathrm{CONJ}$} & \multicolumn{2}{|c|}{ Total } \\
\hline & E & $P$ & E & $\mathrm{P}$ & E & $\mathrm{P}$ & E & $\mathrm{P}$ & $\mathrm{E}$ & $\mathrm{P}$ & $\mathrm{E}$ & $\mathrm{P}$ & $\mathrm{E}$ & $\mathrm{P}$ & $\mathrm{E}$ & $\mathrm{P}$ & E & $P$ \\
\hline$/ \mathrm{p} /$ & 5.06 & 1.23 & 4.46 & 0.96 & 1.82 & 0.16 & 3.95 & 2.84 & 0 & 0 & 4.03 & 0.79 & 0 & 0 & 0 & 0 & 4.18 & 1.04 \\
\hline$/ \mathrm{b} /$ & 2.40 & 2.51 & 2.50 & 4.09 & 2.27 & 22.54 & 1.86 & 6.26 & 0 & 0 & 3.93 & 3.98 & 0.41 & 4.88 & 4.06 & 3.84 & 2.61 & 4.58 \\
\hline$/ \mathrm{m} /$ & 4.47 & 9,37 & 3.11 & 11.74 & 4.66 & 0.66 & 2.55 & 8.15 & 4.03 & 6.22 & 2.88 & 7.34 & 12.34 & 8.33 & 0 & 4.70 & 4 & 8.55 \\
\hline$/ \mathrm{f} /$ & 2.30 & 2.15 & 2.30 & 2.67 & 10.36 & 0 & 1.86 & 2.65 & 1.79 & 0 & 1.54 & 1.97 & 2.88 & 0.57 & 2.81 & 0 & 2.78 & 1.93 \\
\hline$/ \mathrm{v} /$ & 1.24 & 2.70 & 1.89 & 2.76 & 12.64 & 0.83 & 2.55 & 2.46 & 0.44 & 4.26 & 3.08 & 3.18 & 4.11 & 0.57 & 0.62 & 87.60 & 2.58 & 3.85 \\
\hline$/ \mathrm{t} /$ & 10.89 & 10.03 & 12.38 & 10.27 & 20.95 & 3.24 & 13.95 & 7.59 & 32.73 & 0 & 9.66 & 10.27 & 5.76 & 3.44 & 14.68 & 0 & 12.17 & 9.03 \\
\hline$/ \mathrm{d} /$ & 5.43 & 6.74 & 669 & 7.18 & 2.61 & 17.22 & 3.72 & 6.64 & 0 & 8.85 & 16.64 & 20.72 & 4.93 & 8.34 & 32.81 & 0 & 7.89 & 9.62 \\
\hline$/ \mathrm{n} /$ & 12.15 & 10.70 & 16.44 & 9.53 & 23.12 & 2.16 & 12.09 & 11.76 & 2.24 & 20.32 & 8.22 & 10.23 & 25.10 & 25.86 & 34.68 & 0 & 13.55 & 10.23 \\
\hline$/ 1 /$ & 7.65 & 5.41 & 9.74 & 8.19 & 0.56 & 0.99 & 16.27 & 5.88 & 1.79 & 0.32 & 7,72 & 1.13 & 4.11 & 1.43 & 2.50 & 2.56 & 7.08 & 4.62 \\
\hline$/ \mathrm{r} /$ & 15.35 & 12.69 & 14.14 & 11.47 & 16.05 & 26.28 & 17.44 & 9.29 & 5.38 & 2.29 & 10.61 & 10.02 & 11.93 & 10.34 & 3.75 & 0 & 13.93 & 12.64 \\
\hline$|\mathrm{z}|$ & 5.81 & 3.27 & 0.94 & 3.73 & 1.59 & 11.98 & 2.32 & 8.34 & 8.52 & 1.31 & 8.07 & 1.67 & 3.70 & 0 & 2.18 & 0.42 & 5.04 & 3.81 \\
\hline$/ \mathrm{s} /$ & 11.03 & 6.35 & 8.52 & 6.08 & 1.25 & 1.58 & 14.41 & 6.83 & 14.79 & 0 & 9.96 & 6.87 & 19.34 & 0.57 & 0 & 0 & 9.86 & 5.71 \\
\hline$/ \check{\mathbf{s}} /$ & 1.82 & 3.67 & 2.23 & 3.45 & 0 & 0 & 0.93 & 0.94 & 0.89 & 2.62 & 0.74 & 6.04 & 0 & 0.57 & 0 & 0 & 1.41 & 3.49 \\
\hline $\mid \check{\mathbf{z}} /$ & 0.14 & 0.11 & 0.40 & 0.13 & 0 & 0 & 0 & 0.18 & 0 & 0 & 0 & 0 & 0 & 0 & 0 & 0 & 0.12 & 0.08 \\
\hline$/ \check{c} /$ & 0.46 & 0.35 & 0.40 & 0.23 & 0 & 0 & 0.23 & 1.51 & 3.13 & 3.93 & 0.69 & 0.12 & 0.41 & 4.02 & 0.31 & 0 & 0.49 & 0.45 \\
\hline$/ \mathrm{j} /$ & 1.60 & 2.47 & 1.28 & 1.93 & 0 & 0.16 & 0 & 1.13 & 0 & 3.27 & 0.79 & 1.21 & 0 & 0.28 & 0 & 0 & 1.13 & 1.93 \\
\hline$/ \mathrm{g} /$ & 2.45 & 1.72 & 2.77 & 1.24 & 0.79 & 0.16 & 1.86 & 2.27 & 0 & 0.32 & 1.34 & 2.22 & 0 & 3.16 & 0 & 0 & 1.98 & 1.61 \\
\hline$/ \mathrm{k} /$ & 7.30 & 3.51 & 7.37 & 4.19 & 1.25 & 0.24 & 2.32 & 2.84 & 0 & 34.09 & 6.42 & 3.64 & 3.70 & 8.90 & 0.93 & 0.85 & 6.13 & 4.01 \\
\hline$/ \mathrm{y} /$ & 1.22 & 4.74 & 1.42 & 3.13 & 0 & 5.49 & 0.69 & 1.32 & 0 & 2.29 & 0.64 & 1.55 & 1.23 & 9.48 & 0 & 0 & 0.98 & 3.98 \\
\hline$/ \mathrm{h} /$ & 1.58 & 10.18 & 1.01 & 6.67 & 0 & 6.23 & 0.93 & 11 & 24.21 & 9.83 & 3.03 & 6.58 & 0 & 9.19 & 0.93 & 0 & 2 & 8.74 \\
\hline
\end{tabular}

Note: $\mathrm{E}=$ English, $\mathrm{P}=$ Persian, $\mathrm{ADJ}=$ adjective, $\mathrm{PREP}=$ preposition, $\mathrm{ADV}=$ adverb, $\mathrm{PRON}=$ pronoun, $\mathrm{DET}=$ determiner, $\mathrm{CONJ}=$ conjunction.

Analyzing the collected data in English with respect to the frequency of each consonant in each PS to all consonants in all PSs yielded these results. In nouns, adjectives, prepositions, adverbs, pronouns, verbs, determiners, and conjunctions, $/ \mathrm{r} /, / \mathrm{n} /, / \mathrm{n} /, / \mathrm{r} /, / \mathrm{t} /, / \mathrm{d} /, / \mathrm{n} /$, and $/ \mathrm{n} /$ had the highest frequencies respectively. 


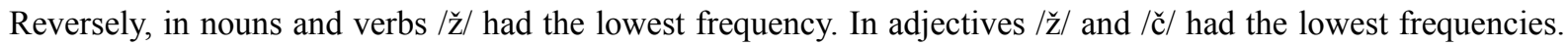
In prepositions, $/ \mathrm{j} /, / \breve{s} /, / \breve{z} /, / \mathrm{y} /, / \mathrm{h} /$, and $/ \check{c} /$ had no frequency. $/ \check{z} /$ and $/ \mathrm{j} /$ were two consonants with no frequency in adverbs. In pronouns, no frequency was dedicated to $/ \mathrm{p} /, / \mathrm{b} /, / \mathrm{d} /, / \mathrm{j} /, / \mathrm{g} /, / \mathrm{k} /, / \mathrm{y} /$ and $/ \check{z} / . / \mathrm{p} /, / \mathrm{j} /, / \mathrm{g} /, / \mathrm{h} /, / \mathrm{s} /$, and $/ \check{z} /$ had no frequency among determiners. In conjunctions, $/ \mathrm{p} /, / \mathrm{m} /, / \mathrm{s} /, / \check{\mathrm{z}} /, / \mathrm{g} /, / \mathrm{y} /, / \mathrm{s} /$, and $/ \mathrm{j} /$ had no frequency (Table 5).

In Persian corpus, the analysis of the frequency of each consonant in each PS to all consonants in all PSs displayed that $/ \mathrm{r} /, / \mathrm{m} /$ and $/ \mathrm{r} /, / \mathrm{r} /, / \mathrm{n} /, / \mathrm{n} /, / \mathrm{d} /$ and $/ \mathrm{t} /, / \mathrm{n} /$, and $/ \mathrm{v} /$ had the highest frequencies in the PSs of nouns, adjectives, prepositions, adverbs, pronouns, verbs, determiners, and conjunctions respectively. However, in nouns, adjectives, adverbs, and verbs, $/ \check{z} /$ had the lowest frequency. In prepositions $/ \check{\mathbf{s}} /, / \bar{z} /, / \check{c} /$, and $/ \mathrm{f} /$ had no frequency. $/ \mathrm{p} /, / \mathrm{b} /, / \mathrm{f} /, / \mathrm{t} /, / \mathrm{s} /$, and $/ \check{z} /$ had no frequency in pronouns. In PS of determiners, $/ \mathrm{p} /, / \mathrm{z} /$, and $/ \check{z} /$ had the lowest frequency. In conjunctions, fourteen phonemes had no frequency including $/ \mathrm{p} /, / \mathrm{f} /, / \mathrm{t} /, / \mathrm{d} /, / \mathrm{n} /, / \mathrm{r} /, / \mathrm{s} /, / \breve{s} /$, $/ \check{\mathrm{z}} /, / \breve{\mathrm{c}} /, / \mathrm{j} /, / \mathrm{g} /, / \mathrm{y} /$, and $/ \mathrm{h} /$.

The highest difference between Persian and English FSs of consonants was discovered in nouns, adjectives, prepositions, and verbs. The highest difference was for nouns (Persian nouns, 8973 and English nouns, 6038). In other PSs, no meaningful difference was found. Except conjunctions, in other PSs the frequency of Persian consonants was more than English ones (Table 1) (See also Appendix, Figure 2).

Table 5. The percentage of each Persian and English consonant in each PS to all consonants in all PSs

\begin{tabular}{|c|c|c|c|c|c|c|c|c|c|c|c|c|c|c|c|c|c|c|}
\hline & \multicolumn{2}{|c|}{ NOUN } & \multicolumn{2}{|c|}{ ADJ } & \multicolumn{2}{|c|}{ PREP } & \multicolumn{2}{|c|}{$\mathrm{ADV}$} & \multicolumn{2}{|c|}{ PRON } & \multicolumn{2}{|c|}{ VERB } & \multicolumn{2}{|c|}{ DET } & \multicolumn{2}{|c|}{ CONJ } & \multicolumn{2}{|c|}{ Total } \\
\hline & $\mathrm{E}$ & $\mathrm{P}$ & $\mathrm{E}$ & $\mathrm{P}$ & $\mathrm{E}$ & $\mathrm{P}$ & $\mathrm{E}$ & $\mathrm{P}$ & E & $\mathrm{P}$ & $\mathrm{E}$ & $\mathrm{P}$ & $\mathrm{E}$ & $\mathrm{P}$ & $\mathrm{E}$ & $\mathrm{P}$ & $\mathrm{E}$ & $\mathrm{P}$ \\
\hline$/ \mathrm{p} /$ & 2.63 & 0.68 & 0.56 & 0.13 & 0.13 & 0.01 & 0.14 & 0.09 & 0 & 0 & 0.69 & 0.11 & 0 & 0 & 0 & 0 & 4.18 & 1.04 \\
\hline$/ \mathrm{b} /$ & 1.24 & 1.40 & 0.31 & 0.55 & 0.17 & 1.67 & 0.06 & 0.20 & 0 & 0 & 0.68 & 0.58 & 0 & 0.10 & 0.11 & 0.04 & 2.61 & 4.58 \\
\hline$/ \mathrm{m} /$ & 2.32 & 5.21 & 0.39 & 1.57 & 0.35 & 0.04 & 0.09 & 0.26 & 0.07 & 0.11 & 0.49 & 1.08 & 0.25 & 0.17 & 0 & 0.06 & 4 & 8.55 \\
\hline$/ f /$ & 1.19 & 1.19 & 0.29 & 0.35 & 0.78 & 0 & 0.06 & 0.08 & 0.03 & 0 & 0.26 & 0.29 & 0.06 & 0.01 & 0.07 & 0 & 2.78 & 1.93 \\
\hline$/ \mathrm{v} /$ & 0,64 & 1.50 & 0.24 & 0.37 & 0.95 & 0.06 & 0.09 & 0.08 & 0 & 0.08 & 0.53 & 0.47 & 0.08 & 0.01 & 0.01 & 1.26 & 2.58 & 3.85 \\
\hline$/ \mathrm{t} /$ & 5.66 & 5.57 & 1.57 & 1.38 & 1.58 & 0.24 & 0.51 & 0.24 & 0.62 & 0 & 1.67 & 1.51 & 0.12 & 0.07 & 0.40 & 0 & 12.17 & 9.03 \\
\hline$/ \mathrm{d} /$ & 2.82 & 3.74 & 0.85 & 0.96 & 0.19 & 1.28 & 0.13 & 0.21 & 0 & 0.16 & 2.87 & 3.06 & 0.10 & 0.17 & 0.90 & 0 & 7.89 & 9.62 \\
\hline$/ \mathrm{n} /$ & 6.32 & 5.95 & 2.09 & 1.28 & 1.74 & 0.16 & 0.44 & 0.38 & 0.04 & 0.38 & 1.42 & 1.51 & 0.52 & 0.55 & 0.95 & 0 & 13.55 & 10.23 \\
\hline$/ 1 /$ & 3.97 & 3.01 & 1.24 & 1.10 & 0.04 & 0.07 & 0.60 & 0.19 & 0.03 & 0.01 & 1.46 & 0.16 & 0.08 & 0.03 & 0.06 & 0.03 & 7.08 & 4.62 \\
\hline$/ \mathrm{r} /$ & 7.98 & 7.05 & 1.80 & 1.57 & 1.21 & 1.95 & 0.64 & 0.30 & 0.10 & 0.04 & 1.83 & 1.48 & 0.24 & 0.22 & 0.10 & 0 & 13.93 & 12.64 \\
\hline$|z|$ & 3.02 & 1.82 & 0.12 & 0.50 & 0.12 & 0.89 & 0.08 & 0.27 & 0.16 & 0.02 & 1.39 & 0.30 & 0.07 & 0 & 0.06 & 0.01 & 5.04 & 3.81 \\
\hline$/ \mathrm{s} /$ & 5.73 & 3.53 & 1.08 & 0.81 & 0.09 & 0.11 & 0.53 & 0.22 & 0.28 & 0 & 1.72 & 1.01 & 0.40 & 0.01 & 0 & 0 & 9.86 & 5.71 \\
\hline$/ \check{\mathbf{s}} /$ & 0.94 & 2.04 & 0.28 & 0.46 & 0 & 0 & 0.03 & 0.03 & 0.01 & 0.04 & 0.12 & 0.89 & 0 & 0.01 & 0 & 0 & 1.41 & 3.49 \\
\hline$|\check{\mathbf{z}}|$ & 0.07 & 0.06 & 0.05 & 0.01 & 0 & 0 & 0 & 0.01 & 0 & 0 & 0 & 0 & 0 & 0 & 0 & 0 & 0.12 & 0.08 \\
\hline /̌́c/ & 0.24 & 0.19 & 0.05 & 0.03 & 0 & 0 & 0 & 0.04 & 0.06 & 0.07 & 0.12 & 0.01 & 0 & 0.08 & 0 & 0 & 0.49 & 0.45 \\
\hline$/ \mathrm{j} /$ & 0.83 & 1.37 & 0.16 & 0.26 & 0 & 0.01 & 0 & 0.03 & 0 & 0.06 & 0.13 & 0.17 & 0 & 0.01 & 0 & 0 & 1.13 & 1.93 \\
\hline$/ g /$ & 1.27 & 0.96 & 0.35 & 0.16 & 0.06 & 0.01 & 0.06 & 0.07 & 0 & 0.01 & 0.23 & 0.32 & 0 & 0.06 & 0 & 0 & 1.98 & 1.61 \\
\hline$/ \mathrm{k} /$ & 3.79 & 1.95 & 0.93 & 0.56 & 0.09 & 0.01 & 0.08 & 0.09 & 0 & 0.64 & 1.11 & 0.53 & 0.07 & 0.19 & 0.02 & 0.01 & 6.13 & 4.01 \\
\hline$/ \mathrm{y} /$ & 0.63 & 2.63 & 0.18 & 0.42 & 0 & 0.40 & 0.02 & 0.04 & 0 & 0.04 & 0.11 & 0.22 & 0.02 & 0.20 & 0 & 0 & 0.98 & 3.98 \\
\hline$/ \mathrm{h} /$ & 0.82 & 5.66 & 0.12 & 0.89 & 0 & 0.46 & 0.03 & 0.35 & 0.46 & 0.18 & 0.52 & 0.97 & 0 & 0.19 & 0.02 & 0 & 2 & 8.74 \\
\hline
\end{tabular}

Note: $\mathrm{E}=$ English, $\mathrm{P}=$ Persian, $\mathrm{ADJ}=$ adjective, $\mathrm{PREP}=$ preposition, $\mathrm{ADV}=$ adverb, $\mathrm{PRON}=$ pronoun, $\mathrm{DET}=$ determiner, $\mathrm{CONJ}=$ conjunction.

\subsection{The FS of Persian and English Consonants in Terms of MA}

The analysis of data according to MA was provoking as well. Stops and affricates comprised the highest and the lowest frequencies among all consonants in Persian. As for the English consonants, stops and glides embraced the highest and the lowest frequencies among all consonants (Table 6). 
Except stops and liquids, in other MAs, the Persian consonants were more frequent than the English ones. Stops, fricatives, liquids, and glides contributed more difference to the Persian and English FSs of consonants than affricates and nasals. It should be mentioned that stops indicated the most difference between English and Persian. The results of $x^{2}$ displayed a significant difference between the FS of English and Persian consonants with respect to all MAs (Tables 6 and 7) (See also Appendix, Figure 3).

Table 6. The FS of common standard English and Persian consonants based on MA and PA

\begin{tabular}{|c|c|c|c|c|c|c|c|c|c|c|c|c|c|c|c|}
\hline $\begin{array}{l}\text { Place } \\
\text { manner }\end{array}$ & & \multicolumn{2}{|c|}{ bilabial } & \multicolumn{2}{|c|}{ labiodental } & \multicolumn{2}{|c|}{ alveolar } & \multicolumn{2}{|c|}{ palato-alveolar } & \multicolumn{2}{|c|}{ velar } & \multicolumn{2}{|c|}{ glottal } & \multicolumn{2}{|c|}{ total } \\
\hline & 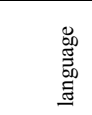 & 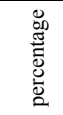 & 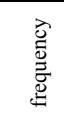 & 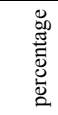 & 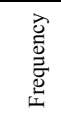 & 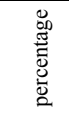 & 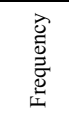 & 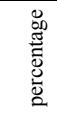 & 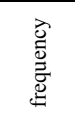 & 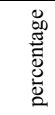 & 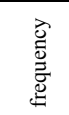 & 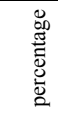 & 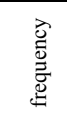 & 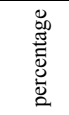 & 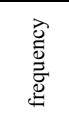 \\
\hline \multirow{2}{*}{ Stop } & Persian & 5.62 & 908 & & & 18.65 & 3012 & & & 5.63 & 909 & & & 29.9 & 4829 \\
\hline & English & 6.79 & 789 & & & 20.07 & 2330 & & & 8.12 & 943 & & & 34.98 & 4062 \\
\hline \multirow{2}{*}{ fricative } & Persian & & & 5.79 & 935 & 9.53 & 1539 & 3.58 & 578 & & & 8.74 & 1411 & 27.64 & 4463 \\
\hline & English & & & 5.36 & 623 & 14.91 & 1731 & 1.54 & 179 & & & 2 & 233 & 23.81 & 2766 \\
\hline \multirow{2}{*}{ affricate } & Persian & & & & & & & 2.39 & 386 & & & & & 2.39 & 386 \\
\hline & English & & & & & & & 1.62 & 189 & & & & & 1.62 & 189 \\
\hline \multirow{2}{*}{ nasal } & Persian & 8.55 & 1381 & & & 10.23 & 1652 & & & & & & & 18.78 & 3033 \\
\hline & English & 4 & 465 & & & 13.55 & 1574 & & & & & & & 17.55 & 2039 \\
\hline \multirow{2}{*}{ liquid } & Persian & & & & & 17.26 & 2787 & & & & & & & 17.26 & 2787 \\
\hline & English & & & & & 21.01 & 2440 & & & & & & & 21.01 & 2440 \\
\hline \multirow{2}{*}{ glide } & Persian & & & & & & & & & 3.98 & 644 & & & 3.98 & 644 \\
\hline & English & & & & & & & & & 0.98 & 114 & & & 0.98 & 114 \\
\hline \multirow[t]{2}{*}{ total } & Persian & 14.17 & 2289 & 5.79 & 935 & 55.67 & 8990 & 5.97 & 964 & 9.61 & 1553 & 8.74 & 1411 & & 16142 \\
\hline & English & 10.79 & 1254 & 5.36 & 623 & 69.54 & 8075 & 3.16 & 368 & 9.10 & 1057 & 2 & 233 & & 11609 \\
\hline
\end{tabular}

Table 7. Results of $x^{2}$ for the distribution of common standard consonants in English and Persian regarding MA

\begin{tabular}{cccccccc}
\hline & stop & fricative & affricate & nasal & liquid & glide \\
\hline Chi square & 66.167 & 398.369 & 66.694 & 194.802 & 2645.254 & 370.580 \\
Significance & $.000 *$ & $.000 *$ & $.000 *$ & $.000 *$ & $.000 *$ & $.000 *$ \\
\hline
\end{tabular}

\subsection{The FS of Persian and English Consonants in Terms of PA}

Concerning PA, among Persian consonants, alveolars and labiodentals included the highest and the lowest frequencies. In case of English consonants, alveolar and glottal included the highest and the lowest frequencies (Table 6).

Table 8. Results of $x^{2}$ for the distribution of common standard consonants in English and Persian regarding PA

\begin{tabular}{lcccccc} 
& bilabial & Labio-dental & alveolar & Palato-alveolar & velar & Glottal \\
\hline Chi square & & & & & & \\
Significance & 302.350 & 65.725 & 49.061 & 266.679 & 94.259 & 844.090 \\
& $.000 *$ & $.000 *$ & $.000 *$ & $.000 *$ & $.000 *$ & $.000 *$ \\
\hline
\end{tabular}


Except alveolars, in other PAs, the Persian consonants were more frequent than the English ones. The frequency of Persian and English consonants among labiodentals and velars were approximately the same while other PAs suggested a higher degree of difference between the FS of Persian and English consonants. Alveolars indicated the highest degree of difference between Persian and English FSs of consonants. Like MAs, the results of $x^{2}$ showed a significant difference between English and Persian regarding all PAs (Tables 6 and 8) (See also Appendix, Figure 4).

\section{Discussion, Conclusion and Implications}

Few studies have been carried out dealing with the FS of consonants. Tackling the FS of languages according to MA and PA can lead to outstanding results for the scholars of some relevant fields. In addition, the investigation of consonants in terms of PSs is also crucial in such investigations.

Results of this study indicated that in $/ \mathrm{r} /$ and $/ \check{\mathbf{z}} /$ both languages have the highest and lowest frequencies respectively while, on the other hand, there was a significant difference between the distribution of eleven Persian consonants and their English counterparts. Furthermore, the frequency of consonants had the highest level of distribution among nouns in both languages with the exception of $/ \mathrm{b} /, / \mathrm{m} /, / \mathrm{v} /, / \mathrm{l} /$ and $/ \mathrm{z} /$ in Persian and /d/ in English. The highest difference between English and Persian consonants was discovered in nouns, adjectives, propositions and adverbs. Moreover, both in Persian and English, some consonants had no frequency in some specific PSs. For instance, frequency of /ž/ among pronouns, determiners, and conjunctions was zero in both languages. Secondly, the frequency of consonants among content words was more than function words with the exception of prepositions which had a high frequency. Finally, concerning the MA and PA both Persian and English had more frequencies of stops and alveolars but with different degrees. Finally, regarding MA and PA, there came out a complete difference between English and Persian in all MAs and PAs.

The results of the present study were to some extent compatible with the previous studies. Mousavi Torbati (1968), in his study, labeled $/ \mathrm{n} /$ as the most frequent Persian consonant, while in this study, $/ \mathrm{n} / \mathrm{received}$ the second place after $/ \mathrm{r} /$ as the most frequent one. Samareh (1993), who investigated the frequency of consonants in the CVCC consonant clusters, and Mohammadifar (1990) concluded $/ \mathrm{r} /$ as the most frequent Persian consonant in their studies which were consistent with the findings of the present study. The present study found /ž/ as the least frequent consonant which confirmed Mousavi Torbati's and Samareh's results. However, the study conducted by Mohammadifar (1990) displayed a nearly opposite result. He found /d/ as the least frequent.

Generally speaking, majority of the findings on Persian and English FSs by themselves and with respect to PS, MA, and PA support the similarity of both languages to some extent which paves the way for this claim that the existing similarities between Persian and English may root in their common protolanguage.

This study has brought out several implications. First of all, it can contribute to the field of linguistics. Since one pursuit of the linguists is tracing the intrinsic quality of languages worldwide, the existing similarities between Persian and English can help them formulate general rules on the typological features of the two languages.

Second, the study can theoretically feed phonetics studies as a branch of general linguistics. A high frequency of a class of consonants in terms of MA or PA in a language can exhibit that the language employs that PA or MA more than other places and manners of articulation. This fact can lead to the theory of features that a language can be realized by its most frequent features i.e. PA and MA. For example, it can be said that if a language has the highest frequency of $/ \mathrm{r} /$ and $/ 1 /$ than other phonemes, then it might be claimed that the language is identifiable by features of liquid (MA) and alveolar (PA).

Third, the study significantly contributes to the Educational System of English as foreign language teaching and applied linguistics. It can be an efficient source for both language teachers and applied linguists. That is, for instance, less frequent consonants and PSs in English should be more focused on in teaching English in EFL contexts. To be more elaborative, the impact of L1 phonetic dissimilarity on L2 learner's acquisition of L2 phonetic segments (Aoyama, Flege, Guion, Akhame-Yamada, \& Yamada, 2004), the effect of the frequency of L1 input on successful L2 pronunciation (Aliaga-García, 2007), the effect of phoneme and feature frequency on the order of acquisition of consonants (Yamaguchi, 2007) and the effect of overlapping distributional patterns in L1 and L2 on phoneme production (Vokic, 2008) support the pedagogical importance of the phonetic frequency.

Finally syllabus designers also can benefit from the way Persian and English are similar and different. It is generally believed that those aspects of the target language which are similar to those of the native language are positively transferred and consequently learnt easily. But as far as target and native language features are different, the risk of interference from the native language increases. Taking into account such an important issue, syllabus designers can focus more on the discrepant language aspects which are usually demanding for children 
to overcome.

\section{Limitations}

The observations presented in this study do not necessarily reject the following limitations. The first question that bursts out is why the same number of consonants in each language has not been involved in the study. The main reason is that the present study is context-based and the lexicons are selected as the unit for determining the contexts which should be of the same length in both languages. The disharmony between the frequency of Persian and English consonants in the contexts of the same length may origin in a variety of factors such as different word length, different number of vowels in each language, genre, and writing style (choice of word).

Another limitation of the study is that the trivial differences between consonants counterparts in two languages have been overlooked. For instance, in English there is lateral and retroflex /r/ while its Persian counterpart does not exactly overlap with it. The corpus of this study was selected from written language and trivial differences in the way phonemes are articulated can not threaten the findings.

At last, it could be announced that some of the PSs might be divided into different sub-branches. For instance, conjunctions, connectives, and interjections are categorized as a large group named conjunctions. The present study has considered these different types of a part of speech under one general part of speech. That is, for example, all discourse markers are known as conjunctions. It is so, because consistency is what the study needs. It was viewed that some types of a part of speech can have a very low frequency of consonants or may not have any frequency.

\section{Further Research}

There are many specific issues that can be taken up in future research. As mentioned before, the present study was designed according to the number of words embedded in the context of newspapers fragments; it was context-based. Similar studies with focus on the equal number of consonants, consonant clusters of different types, and words of the same length are suggested too.

In the present study no attention was directed towards the minimal differences between consonants in the two languages. More studies are suggested dealing with the trivial differences between consonants contrastively. Moreover, in the present study, the distinctive features of consonants were taken into account, and the possible allophones of each consonant were neglected. To say, the consonant $/ \mathrm{p} /$ can have three different allophones coming at the beginning, medial or final positions of a word. Some allophone-based studies in line with the design of the present study are proposed as well.

This study is genre-bound. That is, the context of newspaper may have had an effect on the frequency of consonants. A change in the genre of corpus may lead to different findings. We would like to suggest similar studies based on literary and scientific corpora, the different intentions accompanied with such texts may lead to different results. For example, in literary texts authors usually use techniques like alliteration and repetition in sounds to make the language more influential and this can cause a change in frequency of phonemes.

The way PSs were dealt with was somehow unique to this study. That is, for the sake of simplicity in the procedure of the study, many categories of terms were classified into just one category. More studies are suggested to classify PSs the way they are categorized in their languages.

The present study pertained to merely one aspect of research in the domain of FS. That is, it just dealt with the frequency of consonants and neglected the great role that vowels have in a linguistic context. This issue can be addressed to see if the frequency of vowels is in line with consonants or not, of course with attention to the differences that exist between the Persian consonants and their counterparts in English.

It is a wholly believed opinion that the channel of production of language has some bearings on the produced language; phonemes of each language can be subject to such a bearing in terms of frequency. With a change in the channel of production, a change in the FS of the language is probable. This study employed the written language as the corpus but the results are not a valid indication for oral or spoken language. Oral corpus can be a good domain for future studies.

At last but not least, as future research proceeds, an important task will be to investigate the FS of two languages regarding content and function words. This itself brings some new questions into prominence: what is the FS of English and Persian regarding content and function words? What kinds of phonemes are common among function words? Is there any zero-frequency for phonemes in function words and if so, what can be implied from this? 


\section{Acknowledgments}

Our heartfelt thanks go to Dr. Mehrzad Mansouri who was of abundant help and inspiration during the different stages of doing the research, and provided us with invaluable sources to complete the study. Equally, we would also like to express our gratitude to Dr. Milad Sameri who provided us with valuable information on the format of the paper.

\section{References}

Aliaga-García, C. (2007). The role of phonetic training in L2 speech learning. Phonetics Teaching \& Learning Conference PTLC.

Aoyama, K., Flege, J. E., Guion, S. G., Akhame-Yamada, R., \& Yamada, T. (2004). Perceived phonetic dissimilarity and L2 speech learning: The case of Japanese /r/ and English /1/ and /r/. Journal of Phonetics, 32, 233-250. http://dx.doi.org/10.1016/S0095-4470(03)00036-6

Arzhang, G. (2000). The grammar of modern Persian. Tehran: Qatreh Press.

Assadi, S. H. S. (2007). Sound deletion in colloquial Persian. SaarrbrÜcken, 597-600.

Davidson, L. (2006). Phonetics, phonology, or frequency: Influences on the production of non-native sequences. Journal of Phonetics, 34, 104-137. http://dx.doi.org/ 10.1016/j.wocn.2005.03.004.

Demirezen, M. (2010). The specification of the difficulties in the perception and articulation of the English schwa phoneme by Turkish English teachers and students. Procedia Social and Behavioral Sciences, 2, 1572-1576. http://dx.doi.org/ 10.1016/j.sbspro.2010.03.238.

Giannoni, D. S. (2002).Worlds of gratitude: A contrastive study of acknowledgement texts in English and Italian research articles. Applied Linguistics, 23(1), 1-3. http://dx.doi.org/10.1093/applin/23.1.1

Guirao, M., \& Jurado, M. A. G. (1990). Frequency of occurrence of phonemes in American Spanish. Revue québécoise de linguistique, 19(2), 135-149.

Hogan, P. T., Bowles, R. P., Catts, H. W., \& Storkel, H. L. (2011). The influence of neighborhood density and word frequency on phoneme awareness in 2 nd And 4th grades. Journal of Communication Disorders, 44, 49-58. http://dx.doi.org/ 10.1016/j.jcomdis.2010.07.002.

Jefferies, E., Grogan, J., Mapelli, C., \& Isella, V. (2012). Paced reading in semantic dementia: Word knowledge contributes to phoneme binding in rapid speech production. Neuropsychologia, 50, 723-732. http://dx.doi.org/ 10.1016/j.neuropsychologia.2012.01.006.

Khanlari, P, N. (2000). The historical grammar of the Persian language. Tehran: Tous Press.

Khanlari, P, N. (2007). The Persian language grammar. Tehran: Tous Press.

Koo, H. (2011). A weighted finite-state transducer implementation of phoneme rewrites rules for English to Korean pronunciation conversion. Procedia-Social and Behavioral Sciences, 27, 202-208. http://dx.doi.org/ 10.1016/j.sbspro.2011.10.599.

Kuperman, V., Ernestus, M., \& Baayen, H. (2008). Frequency distributions of uniphones, diphones, and triphones in spontaneous speech. J. Acoust. Soc. Am, 124(6), 3897-3908. http://dx.doi.org/10.1121/1.3006378

Ling, L. E., \& Grabe, E. (1999). A contrastive study of prosody and lexical stress placement in Singapore English and British English. Language and Speech, 42(1), 39-56. http://dx.doi.org/10.1177/00238309990420010201

Macizo, P., \& Van Petten, C. (2007). Syllable frequency in lexical decision and naming of English words. Reading and Writing, 20, 295-331. http://dx.doi.org/10.1007/s11145-006-9032-z

MacKay, I. R. A., Meador, D., \& Flege, J. E. (2001). The identification of English consonants by native speakers of Italian. Phonetica, 58, 103-125. http://dx.doi.org/10.1159/000028490

Mansouri, M. (2009). The frequency system of phonemes in Persian. Ilam: Ilam University Press.

Moates, D., Stockmal, V., \& Bond, Z. (2004). Frequency effects in phoneme processing. Acoustical Society of America Digital Library, 115(5), 2395-2395.

Mohammadifar, M. R. (1990). Language and information. Journal of Linguistics, 6(1), 2-22

Monnin, J., lœvenbruck, H., \& Beckman, M. E. (2007). The influence of frequency on word-final obstruent acquisition in Hexagonal French. SaarrbrÜcken, 1569-1572. 
Mousavi Torbati, S. (1968). The frequency of the use of phonemes in written Persian. Unpublished M.A thesis. Tehran University.

Newman, E. H., Tardif, T., Huang, J., \& Shu, H. (2011). Phonemes matter: The role of phoneme-level awareness in emergent Chinese readers. Journal of Experimental Child Psychology, 108, 242-259. http://dx.doi.org/10.1016/j.jecp.2010.09.001.

Ota, M. (2006). Input frequency and word truncation in child Japanese: Structural and lexical effects. Language and Speech, 49(2), 261-295. http://dx.doi.org/10.1177/00238309060490020601

Sajavaara, K., \& Dufva, H. (2001). Finnish-English phonetics and phonology. IJES, 1(1), 241-256.

Salehuddin, K., Kim Hua, T., \& Maro, M. (2006). Definiteness and indefiniteness: A contrastive analysis of the use of determiners between the Malay language and English. GEMA Online Journal of Language Studies, 6(1), 21-30.

Samareh, Y. (1993). The phonetics of the Persian language: Phonemes and phoneme structure of syllables. Tehran: University Press Center.

Sandoval, A. M., Toledano, D. T., Torre, R., Garrote, M., \& Guirao, J. M. (2007). Developing a phonemic and syllabic frequency inventory for spontaneous spoken Castilian Spanish and their comparison to text-based inventories. Madrid: the Spanish Ministry of Science and Technology.

Santiago, J., Pérez, E., Palma, A., \& Stumberger, J. P. (2007). Syllable, word, and phoneme frequency effects in Spanish phonological speech errors: The David effect on the source of the error. MIT Working Papers in Linguistics, 53, 265-303.

Tambovtsev, Y., \& Martindale, C. (2007). Phoneme frequencies follow a Yule distribution: The form of the phonemic distribution in world languages. Theoretical Linguistics, 4(2), 6-14.

Timmer, K., \& Schiller, N. O. (in press). The role of orthography and phonology in English: An ERP study on first and second language reading aloud. Brain Research. Retrieved from http://www.sciencedirect.com.

Tsoi Wai Chuen, T. (2005). The effect of occurrence frequency of phonemes on second language acquisition: A quantitative comparison of Contones, Mandarin, Italian, German, and American English. Hong Kong: Chinese University of Hong Kong.

Vokic, G. (2008). The role of structural position in L2 phonological acquisition: Evidence from English learners of Spanish as L2. Foreign Language Annals, 41(2), 347-363. http://dx.doi.org/10.1111/j.1944-9720.2008.tb03296.x

Weinberger, S. H., \& Kunath, S. (2009). Towards a typology of English accents. AACL Abstract Book, 104.

Wright, S., Hay, J., \& Bent, T. (2003). Ladies first? Phonology, frequency and the naming conspiracy. California: LSA Publication.

Yamaguchi, N. (2007). Markedness, frequency: Can we predict the order of acquisition of consonants? Proceedings of Lingo, 236-243.

Yeh, C. C. (2004). The relationship of cohesion and coherence: A contrastive analysis of English and Chinese. Journal of Language and Linguistics, 3(2), 243-260.

\section{Note}

Note 1. Abbreviations: Manner of articulation (MA), place of articulation (PA), parts of speech (PS), frequency system (FS) 


\section{Appendixes}

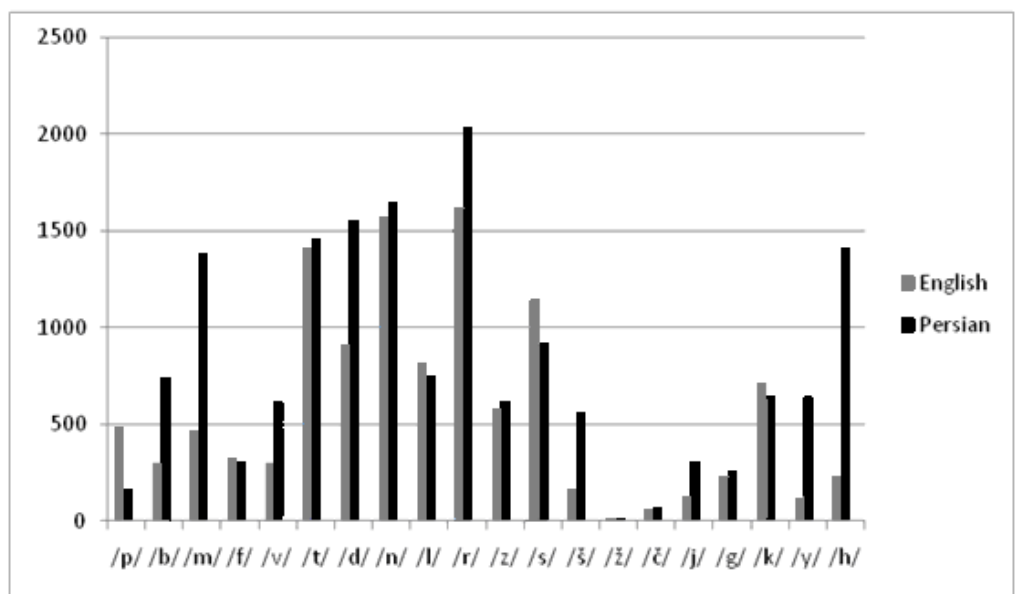

Figure 1. The difference between the frequency of common standard English and Persian consonants

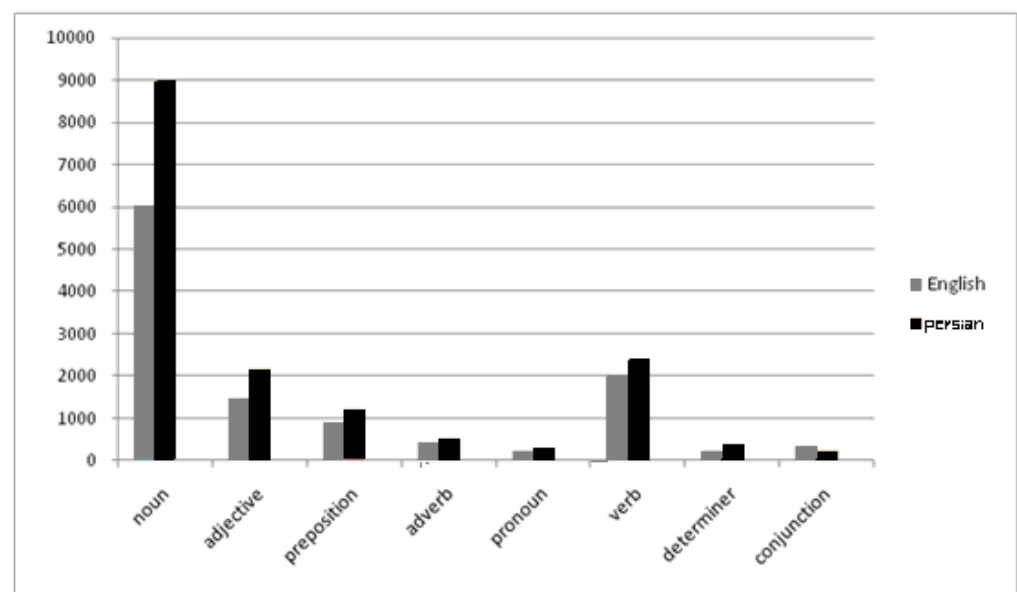

Figure 2. The difference between the frequency of common standard English and Persian consonants in different PS

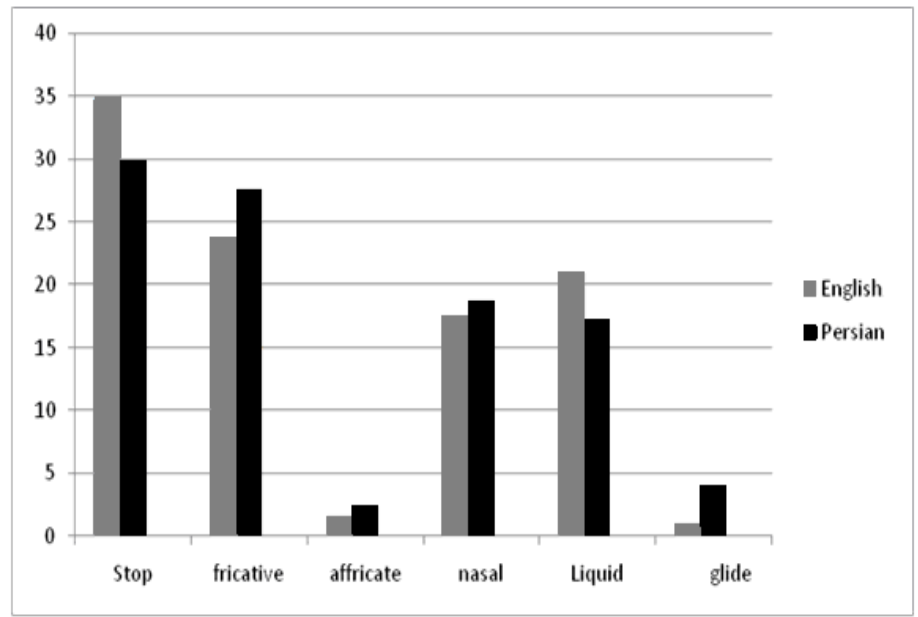

Figure 3. The difference between the frequency of common standard English and Persian consonants in terms of MA 


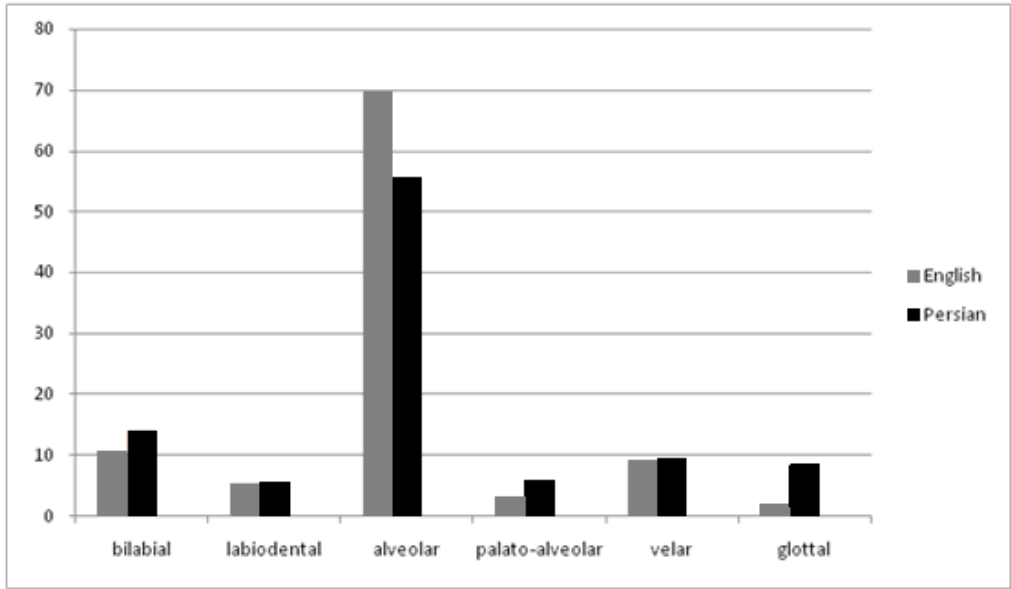

Figure 4. The difference between the frequency of common standard English and Persian consonants in terms of PA 